\title{
HEROÍSMO DE LA VOLUNTAD: LA DIGNIDAD HUMANA Y LA RECUPERACIÓN DEL SENTENCIADO EN EL MÉTODO APAC*
}

\author{
Gilmar Siqueira** \\ Universidade Federal do Pará - UFPA, Brasil \\ gilmarsiqueira126@gmail.com \\ Lafayette Pozzoli*** \\ Pontificia Universidade Católica de São Paulo-PUC, Brasil \\ lafayette@lafayette.pro.br \\ Rogério Cangussu Dantas Cachichi**** \\ Centro Universitário Eurípides de Marília - UNIVEM, Brasil \\ rogeriocangussu@gmail.com
}

Resumen: El objetivo del método APAC es preparar a las personas que cumplen una condena criminal para la reintegración en el seno de la sociedad tras el cumplimiento de la condenación. Lo que se mostrará en este artículo es que la dignidad humana, la responsabilidad, el arrepentimiento y la esperanza son elementos fundamentales en la vida

\footnotetext{
* La abreviatura proviene de Asociación de Protección y Asistencia a los Condenados. Consiste en un sistema humanizado de cumplimiento de pena llevado a cabo por un método, cuya aplicación se da desde hace más de cuarenta años en Brasil. Está basado en doce fundamentos: 1, la participación de la comunidad; 2, el recuperando ayuda al recuperando; 3 , el trabajo; 4, asistencia jurídica; 5 , asistencia a la salud; 6 , el voluntario y su formación; 7, valorización humana; 8, espiritualidad; 9, jornada de liberación con Cristo; 10, el mérito; 11, centro de reintegración social-CRS; 12, la familia.

** Es doctorando en Derecho por la Universidad Federal de Pará y magister en Derecho por el Centro Universiterio Eurípides de Marília - UNIVEM.

*** Es postdoctor en Filosofía del Derecho y del Estado por la Universidad "La Sapienza" (Roma, Italia). Doctor y magíster en Filosofía del Derecho por la PUC/SP. Es profesor y fue jefe de Gabinete en la PUC-SP. Abogado. Consultor evaluador del INEP/MEC para Cursos Jurídicos. Líder del Grupo de Investigación GEDs "Direitos Fundamentais à Luz da Doutrina Social" - Derecho y Fraternidad - PUC-SP. Miembro del Consejo Editorial de la Revista EM TEMPO y de las editoriales Letras Jurídicas y Instituto Memória. Fue profesor asistente en el Curso de Teoría General del Derecho, ministrado por el saudoso Profesor André Franco Montoro - Postgrado PUC-SP.

***** Es magíster en Derecho por el Centro Universitario Eurípides de Marília - UNIVEM/Fundação. Graduado en filosofía (UEL). Miembro del grupo de investigación “GP CERTOS y Políticas Públicas”(UENP), asignado al Directorio de Grupos de Pesquisas del CNPq. Juez Federal de la Subsección Judiciaria de Jacarezinho/PR (Brasil).
} 
humana. Para tal objetivo, se analizará primeramente el ejemplo de Ramón, personaje de la novela La fiel infantería. Partiendo de él, se buscará ver lo que el filósofo José Ortega y Gasset entiende por heroísmo en la voluntad humana. Seguidamente, se abordará la dignidad humana y la posibilidad de despersonalización en un diálogo entre Ortega y Julián Marías. Para terminar, se verá cómo el método APAC, mediante el reconocimiento de la dignidad humana y con estímulo al heroísmo de la voluntad, promueve la plena recuperación de las personas condenadas. Tal recuperación ocurre cuando el ser humano es valorado en todas sus dimensiones y se convierte en protagonista de la propia vida en el ejercicio de la voluntad heroica.

Palabras clave: Método APAC, dignidad humana, resocialización, literatura.

\title{
HEROISM OF THE WILL: HUMAN DIGNITY AND THE RECOVER OF THE PRISONER IN THE APAC METHOD
}

\begin{abstract}
The purpose of the APAC method is to prepare people who are serving a criminal sentence for reentry into society once the sentence has ended. What will be shown in this article is that human dignity, responsibility, regret and hope are fundamental elements in human life. For this, the example of the character Ramón, from the novel $\mathrm{La}$ Fiel Infantería, will be analyzed first. From it, we will try to see what the philosopher José Ortega y Gasset understands by heroism in the human will. Then it will deal with human dignity and the possibility of depersonalization in a dialogue between Ortega and Julián Marías. Finally, it will be seen how the APAC method, through the recognition of human dignity and encouraging the heroism of the will, promotes the recovery of prisoners. Such recovery occurs when the human being is revalued in all its dimensions and discovers how to become the protagonist of his own life in the exercise of the heroic will.
\end{abstract}

Keywords: APAC method, Human Dignity, Resocialization, Literature.

\section{Introducción}

El objetivo del método APAC es preparar a las personas que cumplen una condena criminal para la reintegración al seno de la sociedad tras el cumplimiento de la condena. Tal resocialización del condenado — que, en el método APAC, se convierte en recuperando - será consecuencia de una perspectiva y un tratamiento más profundamente humano, es decir, mediante la conciencia que la persona adquiere de la responsabilidad de 
sus actos y de la necesidad de asumir dicha responsabilidad. Esa conciencia deviene del reconocimiento de la dignidad humana de las personas condenadas.

Lo que se mostrará en este artículo es que la dignidad humana, la responsabilidad, el arrepentimiento y la esperanza son elementos fundamentales en la vida humana. Para cumplir dicho objetivo, se verá primero el ejemplo Ramón, personaje de la novela La fiel infantería, de Rafael García Serrano. Partiendo de él, se intentará ver qué es lo que el filósofo José Ortega y Gasset entiende por heroísmo en la voluntad humana y cómo es la voluntad la que engendra la tragedia — en un sentido que se desarrollará a lo largo de esta investigación-- para la vida humana.

En la segunda parte del artículo, el heroísmo de la voluntad será relacionado expresamente al concepto de dignidad humana para que se entienda cómo la libertad y la responsabilidad son manifestaciones de la dignidad intrínseca a la persona humana. Seguidamente, se analizará la estructura dramática de la vida humana como elemento complementario a la dignidad, o sea, la persona será vista en cuanto dotada de dignidad intrínseca y también de responsabilidad ante la propia vida. La dignidad humana sufre de un menoscabo cuando tiene lugar el proceso de despersonalización.

Finalmente, se verá cómo el método APAC, mediante el reconocimiento de la dignidad humana y por medio del estímulo al heroísmo de la voluntad, promueve la plena recuperación de las personas condenadas. Tal recuperación ocurre cuando el ser humano es valorado en todas sus dimensiones y se convierte en protagonista de la propia vida en el ejercicio de la voluntad heroica.

\section{José Ortega y Gasset y el heroísmo de la voluntad}

Hay más de un medio para explicar una idea y exponerla en una investigación académica como esta. Uno de ellos es el de explicar antes la idea para, en seguida, ilustrarla con algún ejemplo. De esta manera, se podría en este artículo empezar por la exposición de lo que José Ortega y Gasset entiende por heroísmo - tal como aparece en el título de este apartado - para más adelante ofrecer un ejemplo concreto coherente con la teoría del autor español.

Sin embargo, aquí se tomará otro cauce: primero será presentado un ejemplo con el fin de que a posteriori se entienda la teoría de Ortega y Gasset. El ejemplo de este trabajo será el personaje Ramón, de la novela La fiel infantería, del escritor español Rafael García Serrano. Ramón, combatiente voluntario en la Guerra Civil, tenía por modelos a los grandes héroes de la historia: anhelaba él mismo ser grande para que así pudiese construir algo grande. 
A los veintidós años, Ramón se erguía en protagonista y con sus manos amasaba desde años atrás rojo pan de historia. Era justo, pues, ordenar el fuego interior para una gozosa serenidad del bosque que le diese en la vereda paso firme y frente alta. Ramón vivía convencidísimo de que Dios pensaba en él cada minuto, porque también oía en sí mismo el brote de su destino. Ignoraba Ramón que los mozos así, altaneros, taciturnos, predestinados, suelen morir modestamente; que la peor señal de malogro es oír demasiado el crujido de la hierba interior. Con su pequeño historial, su historial único, y el tiempo por compañero, su nombre le sonaba a maravilla. $(1964$, p. 533$)$

En la descripción de la personalidad de Ramón el narrador anticipa su circunstancia, aunque en tono de alerta. Ramón aborrecía la idea de que un soldado muriese sin sus botas: tal era el símbolo para la muerte fuera del campo de batalla, indigna de un soldado — “Bienaventurados los que mueren con las botas puestas", dijo Ramón (1964, p. 589)—. Ese Ramón visionario llegó a los veintitrés años a lo largo del conflicto en que tomó parte. Como pensaba tanto en la gloria, abominaba que los españoles tomaran como ejemplo a Don Quijote - un derrotado, según él:

Ha de prohibirse por decreto la menor simpatía hacia Don Quijote apaleado; que la sienta solamente ese atajo de estúpidos que nos atontan a fuerza de hablar de imperios espirituales. Al chirrión los imperios espirituales. Nosotros queremos tierra de todos los colores y ríos azules y mares verdes, bien poblados de destructores: sultanes, caídes, reyezuelos, caciques, la gran especia del petróleo, el mundo. El dominio sobre los demás y en la cima el Emperador. (1964, p. 537)

Ramón quería que todos supieran por qué luchaban, por qué motivos arriesgaban sus vidas en el campo de batalla. Él conocía bien sus razones. A pesar de ser grandilocuente consigo mismo, era humilde y bondadoso con los demás soldados. Y, tal como anhelaba, era también valeroso en la pelea. Pero Ramón pensaba que el honor y la gloria - o heroísmo - de alguna manera ya le pertenecían; pensaba que su generación tenía un privilegio especial de construir algo bueno, algo nunca antes visto $-\mathrm{y}$ algo justo - para todos. Ramón creía que ya realizaba aquello mismo con que soñaba. Sin embargo, después de un triunfo militar, Ramón tuvo que ser conducido al hospital: sin ninguna herida de guerra, había caído ante la tuberculosis.

De tren a tren va la vida y aunque para un soldado partir no es morir un poco, sino vivir del todo, en aquél momento Ramón pensaba que se moría a chorros, 
generosamente, sin que la muerte le correspondiese con el honor de reservarle una hermosa ocasión de decir adiós al mundo que amaba. Todo se ha acabado con el tren maldito porque — señal de piedra blanca — por vez primera comprueba Ramón que la dificultad, que la adversidad no sólo no le sorprende sonriente, sino que le desbarata el menor intento de alegría. Y donde no hay alegría, no hay soldado, y donde no hay soldado, no hay hombre. Queda, apenas, un pellejo fundado en huesos que va dejándose la sangre por el sendero, sin que el enemigo - eso, sobre todo- haya dado origen a la hemorragia. Es lo mismo que si no hubiese guerra. (1964, p. 580)

Al imaginarse ya un héroe y hasta luchar para concretizar dicho heroísmo, Ramón llegó a creer que lo era ya, que sus pasos — aunque primarios - lo ponían casi al mismo nivel que sus tan admirados héroes del pasado. Por ello, descubrir una tuberculosis, una herida no causada por el enemigo, era para él un sufrimiento tan grande: además de física, era una herida en su orgullo. Ramón no pensó que muchos otros soldados, tan valerosos y sinceros como él mismo, también podrían caer víctimas de enfermedades en medio de las trincheras. Semejante muerte sería, para Ramón, una "muerte indigna”.

Las últimas veinte páginas de la novela describen la enfermedad y muerte de Ramón. Hay dos escenas bastante simbólicas que ilustran la honda tristeza y rebeldía del personaje ante su destino adverso: en la primera lo están llevando, en tren, hasta el hospital de la convalecencia cuando aparecen otros soldados - heridos de guerra- y Ramón les tiene envidia (García Serrano, 1964, p. 585); en la segunda escena, Ramón, ya en el hospital, pone los ojos en otro herido con uno de los brazos amputados y lo ve abrazar a su novia por la cintura con el brazo que le quedaba: "Esteban puede hacerlo, porque está herido y su boca no mancha” (1964, p. 593). Ramón creíase menos que los heridos y se humillaba con los propios pensamientos. Su muerte era segura.

Pero Ramón, Ramón predestinado, Ramón superior, Ramón gibelino, Ramón litigando ante el Dios de los acampados, Ramón alférez, Ramón con su historia, Ramón ha llegado ya — piensa, desobedeciendo al médico—. Ya no duda, ya no se desespera ya no es altanero: ya sólo es un resignado. Lo que jamás hubiese querido ser: un resignado. Algo así como un vencido que no se rebela, que cierra los ojos y codicia el mazazo definitivo. (1964, pp. 591-592)

El heroico Ramón entendía la resignación como una debilidad más: la debilidad de los que no pueden luchar, entre los cuales se encontraba él mismo. Ramón acabó despreciándose a sí mismo con esa rebeldía amarga: fue del heroísmo y de los grandes 
sueños a la autocompasión llena de encono. En los postreros momentos, cuando intentó hacer la señal de la cruz, no tuvo fuerzas y la mano se le cayó encima del rostro en un gesto que parecía avergonzado (García Serrano, 1964, p. 594). Ramón murió como Alonso Quijano: en la cama. Pero, ¿Ramón habrá sido, por lo menos en algún sentido, un héroe? Esto es lo que se intentará ver desde ahora. Para esto, hay que traer a la discusión el concepto de heroísmo de José Ortega y Gasset:

...pero es un hecho que existen hombres decididos a no contentarse con la realidad. Aspiran los tales a que las cosas lleven un curso distinto: se niegan a repetir los gestos que la costumbre, la tradición, en una palabra, los instintos biológicos les fuerzan a hacer. Estos hombres llamamos héroes. Porque ser héroe consiste en ser uno, uno mismo. Si nos resistimos a que la herencia, a que lo circunstante nos impongan unas acciones determinadas es que buscamos asentar en nosotros, y solo en nosotros, el origen de nuestros actos. Cuando el héroe quiere, no son los antepasados en él o los usos del presente quienes quieren, sino él mismo. Y este querer él ser él mismo es la heroicidad. (2016, pp. 80-81)

El heroísmo entonces, para Ortega, reside en la voluntad: no en una voluntad demiúrgica que crea una sucesión de conceptos abstractos, sino en una voluntad que ante todo es la voluntad de resistir. El héroe resiste e incluso se queja como en los versos de Antonio Machado: “QQué difícil es/ cuando todo baja/ no bajar también!” (2001, p. 420). Su lucha es por conservarse a sí mismo, para no hacerse esclavo del ambiente, de las circunstancias y mucho menos de otras personas. "La raíz de lo heroico hállase, pues, en un acto de voluntad", lo ha resumido Ortega y Gasset (2016, p. 83).

Es la voluntad de ser mejor, de madurar con autenticidad en un medio que tal vez intente impedir esa madurez. Para el que tenga la voluntad heroica señalada por Ortega, por lo tanto, la vida será una lucha. La agonía de la persona consistirá en que, a pesar de su voluntad de querer afirmarse, habrá fuerzas dispuestas a paralizarla y quitarla de su camino. Por esa razón insiste Ortega todavía en otro punto importante: la voluntad heroica es la génesis de la tragedia:

La voluntad - ese objeto paradoxal que empieza en la realidad y acaba en lo ideal, pues solo se quiere lo que no es-, es el tema trágico, y una época para quien la voluntad no existe, una época determinista y darwiniana, por ejemplo, no puede interesarse en la tragedia. (2016, p. 83) 
Esto es importante: la voluntad engendra la tragedia, porque solamente se anhela ser lo que todavía no se es. La voluntad, por tanto, mediante la imagen de una vida mejor, de alguien que se quiere ser, moverá a la persona a luchar contra todo aquello que, en su circunstancia, intente alejarla de la imagen; pero la lucha suele ser difícil y no pocas veces la circunstancia adversa parecerá vencer. He aquí el núcleo de la tragedia. Para esa concepción de Ortega, el héroe no fue tirado a una situación en la que no pudo actuar; todo lo contrario: por su propia voluntad ha deseado un objetivo por el que merecía la pena arriesgarse y así aceptó la lucha.

Aquí es menester regresar al personaje Ramón: aunque no se haya dicho al principio de este artículo, en su vida universitaria, Ramón era algo frívolo y no se interesaba demasiado por los grandes problemas. La guerra, sin embargo, lo despertó a otra realidad. Así pudo ver en la construcción de una comunidad mejor y en la victoria sobre el campo objetivos que valían por toda una vida, objetivos que él podría perseguir. Y los persiguió: Ramón luchó, formó amistades y fue valeroso. Pero, habiendo hecho todo esto, ¿por qué todavía murió resentido? Ortega y Gasset lo responde:

De querer ser a creer que se es ya va la distancia de lo trágico a lo cómico. Este es el paso de la sublimidad a la ridiculez. La transferencia del carácter heroico desde la voluntad a la percepción causa la involución de la tragedia, su desmoronamiento, su comedia. El espejismo aparece como tal espejismo. (2016, p. 87)

Cuando Don Quijote fue recibido pomposamente en el palacio de los duques, el narrador cuenta que “...aquél fue el primer día que de todo en todo conoció y creyó ser caballero andante verdadero, y no fantástico..." (Cervantes, 2005, p. 1079). Sin embargo, los duques le recibieron como caballero para burlarse de él. Era una situación patética.

Se considera patética la situación del que, siendo muy poca cosa y con valores muy limitados, cree que es una maravilla de enorme importancia; pienso que es más aún la del que está persuadido de su mínima realidad pero arrastra la imagen de un personaje eminente y extraordinario. (Marías, 1994, p. 120)

Y la burla es más melancólica y dura precisamente porque Don Quijote creía que recibía los honores de caballero andante. Tal episodio tiene íntima relación con las palabras de Ortega que aparecen en la citación anterior: en aquel momento Don Quijote dejó de pensar que era un caballero andante y empezó a verse como uno. De ese modo, la tragedia se transmutó en comedia: cuando el héroe — en el sentido de Ortega — piensa 
que ya es totalmente quien quiere ser, sin margen alguna para evolucionar, abandona la realidad y pasa a creer en el espejismo.

Cuando el ideal deja de mover a la voluntad y se convierte en fantasía, cesa la razón de la lucha: el iluso pensará que ya es aquello que quería ser. Y exigirá el tratamiento correspondiente: en el caso de Ramón, recibir laureles y una muerte en combate, digna de un héroe. Ramón tenía ideales e intentó conquistarlos: pero tenía también un concepto de sí — un espejismo o fantasía — demasiado alto; si al fin de cuentas ya era un héroe, merecería un gran premio, o por lo menos lo que él suponía ser ese gran premio: el honor de morir en combate. Cuando, sin embargo, fue derribado por la tuberculosis, luego sacó la conclusión contraria: si los héroes se morían en combate - con las botas puestas - y él se moría en la cama, entonces él no era ningún héroe. Ramón pasó desde la exaltación de la propia imagen al más terrible desprecio de sí mismo.

La fortaleza supone vulnerabilidad; sin vulnerabilidad no habría siquiera la posibilidad de la fortaleza. Un ángel no puede ser fuerte, porque no es vulnerable. Ser fuerte significa tener la capacidad para recibir una herida. El hombre puede ser fuerte porque puede ser herido. (Pieper, 2018, p. 152)

Ramón podía ser herido. Contaba, por cierto, con que un héroe debía de morir así. Pero Ramón no tenía la virtud de la fortaleza porque no pensaba que la enfermedad y que la fragilidad eran partes de la naturaleza humana. Al verse como un héroe de guerra, se le olvidó que la humanidad — tanto la suya como la de sus prójimos — también es hecha de debilidad; y dicha debilidad, cuyo reconocimiento se da por la humildad, presupone el heroísmo de la voluntad del que habló Ortega y Gasset.

Si la voluntad es alimentada por la idea de lo que todavía no se es, pero que se anhela ser, entonces es menester tener paciencia y humildad de reconocer la debilidad presente a fin de no disminuir el objetivo ni la imagen deseada. Don Quijote, en el palacio de los duques, cayó en ridículo; Ramón, en una cama de hospital, cayó en el desprecio de sí mismo. La tragedia del heroísmo de la voluntad es una lucha que, cuando es verdadera, se extiende por toda la vida. El héroe no se ve mejor que los demás, sino como alguien que todavía no logró mejorar, como alguien todavía amenazado por todo que parece intentar derribarlo.

\section{La dignidad humana y la voluntad heroica}

La voluntad heroica, como se ha visto en la primera parte de este artículo, es la que engendra la circunstancia trágica para la persona: aunque ella reconozca y desee una vida 
mejor de la que tiene, aunque quiera ser una persona mejor de lo que es, para que esto sea posible tendrá que luchar contra todo aquello que de alguna manera intente impedir la mejoría. Dicha batalla es esencialmente humana y muestra el grado de dramaticidad existente en la vida de todas las personas: las posibilidades heroica, patética e incluso de entrega y rendición son comunes a todos. Así se puede entender que la dramaticidad de la vida humana es uno de los elementos reveladores de la dignidad humana:

...en el fondo se trata de tener conciencia de la dignidad objetiva de la persona humana, de que el hombre no puede ser tratado al arbitrio del poder y de la sociedad, porque es objetivamente un ser digno y exigente, portador de unos derechos en virtud de su dignidad, reconocidos, pero no otorgados por la sociedad. (Hervada, 1993, p. 655)

El principio de la dignidad humana reconoce algo que es característico de todas las personas. Pero no establece nada, es decir, no crea una convención denominada dignidad que, una vez positivada, debe ser aceptada por todos. La dignidad humana permanecería aunque no estuviese positivada. Cabe señalar que el principio de la dignidad de la persona humana aparece en el Título I de la Constitución Federal de Brasil del año 1988 (todavía vigente), en su artículo $1 .^{\circ}$ :

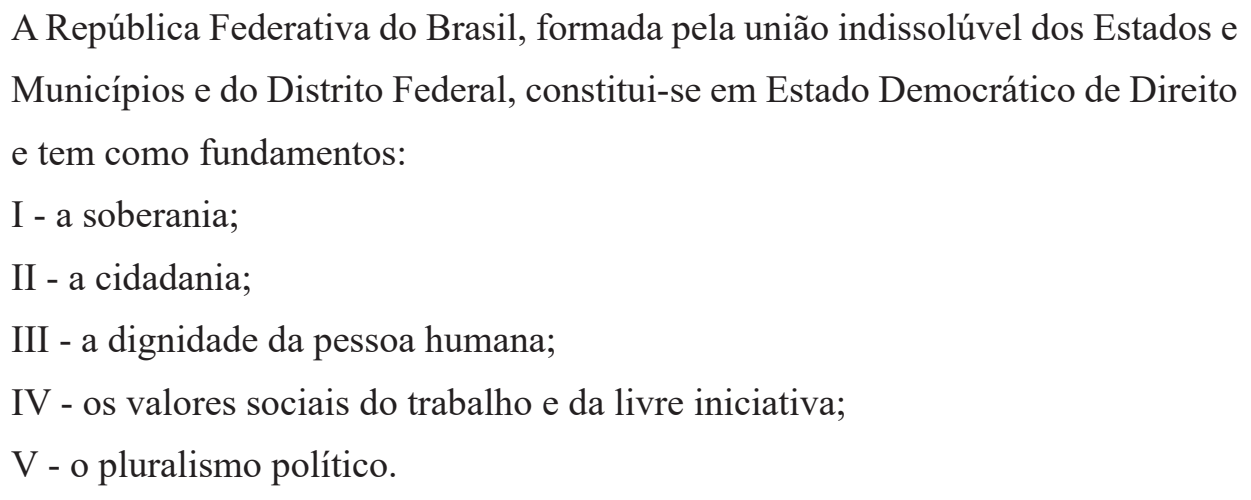

Como no existe determinación específica para la aplicación de dicho principio, se puede comprender que el artículo $3 .^{\circ}$ presenta algunos ejemplos de derechos que garantizan la dignidad de la persona humana. "Nessa seara, não há de olvidar-se que estamos diante de um rol meramente paradigmático que o legislador apresentou para nortear o que deve entender a hermenêutica jurídica no tocante a dignidade humana" (Pozzoli \& Toledo, 2017, p. 180). La dignidad de la persona humana no consiste sencillamente en un atributo positivo, es decir, no nace de la legislación, sino todo lo contrario: el reconocimiento de la dignidad de la persona humana por parte de la Constitución Federal de Brasil existe 
porque el ser humano tiene dignidad desde su origen y la supresión de tal dignidad es un riesgo que la Constitución brasileña buscó expresamente evitar. Como señalan Pozzoli y Rodrigues de Toledo:

Tendo como referência a dignidade do ser humano é fácil identificar seu critério subjetivo, já que cada ser humano possui sua própria dignidade, não perante o Estado, mas perante sua sociedade, o que assim, passa a ter, a dignidade humana, valor em 'pé de igualdade' à vida do homem, vez que, um não tem sentido sem o outro. $(2017$, p. 181$)$

No siendo la dignidad humana un derecho, "mas um atributo intrínseco a todo ser humano" (Pozzoli, Scarmanhã \& Cachichi, 2019, p. 166), tiene ella status ontológico y su reconocimiento por parte del Estado —o de cualquiera que sea el modo de organización de la comunidad política - es imprescindible para que la misma dignidad no sea menoscabada ni convertida en un medio para fines políticos prácticos y temporales. Aunque sea posible la divergencia en su fundamento - si transcendente o inmanente - es menester por lo menos el reconocimiento de su existencia. Solo una persona digna puede tener la posibilidad heroica de arriesgar a elevarse sobre todo aquello que la arrastra hacia abajo, sobre un determinismo fallido y una vida disminuida. Julián Marías llama la atención, por ejemplo, para el riesgo de la disolución en lo social:

Otra forma de atenuación de lo propiamente personal es la disolución en lo social, la subordinación del individuo a un grupo condicionante, por ejemplo, la tribu, fuera de cuyas vigencias compactas queda un limitado espacio libre para la persona como tal. En un grado menor, pero posible en condiciones históricas superiores, y que llegan a nuestros días, la persona puede estar «perdida» en una red de relaciones impersonales. A veces esto no es forzoso, pero se busca por huir de la soledad; esta es inseparable de la condición personal, la acompaña siempre; y a la vez es la soledad la que hace posible toda auténtica compañía. (1997, p. 26)

Tal disolución puede ocurrir cuando la persona se disminuye: tanto por la propia voluntad como por la presión social - los dos elementos, incluso, pueden caer sobre ella concomitantemente- Entonces es como si la persona se abstuviese de su status personal y digno para cumplir determinadas reglas y sentirse abarcada — diluida - en una totalidad más grande. Así acaba por renunciar a la tan temida tragedia de tener que luchar contra las circunstancias adversas; pero, al mismo tiempo, renuncia también al protagonismo de su vida y anula la realización de su dignidad (la realización puede ser 
anulada, aunque la dignidad permanezca existiendo precisamente por su status ontológico en la persona). "Além disso, a dignidade deve ser subentendida por se mostrar como a mais importante valoração inerente a qualquer pessoa humana" (Razaboni Jr., Leão Jr. \& Sanches, 2018, p. 148).

Em uma convivência humana bem constituída e eficiente é fundamental o princípio de que cada ser humano é pessoa, isto é, natureza dotada de inteligência e vontade livre. Por essa razão, possui em si mesmo direitos e deveres, que emanam direta e simultaneamente de sua própria natureza. São direitos e deveres universais, invioláveis e inalienáveis. (Pozzoli \& Toledo, 2017, p. 185)

Tales derechos y deberes pueden ser entendidos también como siendo de la persona para consigo misma. Al mismo tiempo en que reconoce su dignidad intrínseca, la persona se encuentra ante un desafío: el de no entregarse a las circunstancias adversas. Entonces esa dignidad parece traer una obligación a la persona, una responsabilidad con su proyecto de vida y la potencial dificultad de la circunstancia trágica en el caso de tomar el riesgo de intentar realizarse.

Aquí aparece un elemento de lo personal que me parece relevante: la necesidad. A lo estrictamente personal no se puede renunciar sin dejar de ser uno mismo. Esta necesidad ha de conjugarse con la libertad - una paradoja más en esta realidad tan paradójica y que obliga a rehacer la «ontología». La libertad es el fondo de la persona que se es, y el que arriesga u ofrece su vida por motivos personales ejecuta un acto libre y necesario a la vez, en el que se descubre como quien verdaderamente es. La impresión que se expresaría en la fórmula «a pesar de todo» da la clave de esta dimensión de lo personal. (Marías, 1997, p. 30)

“A pesar de todo" es, como señaló Julián Marías, una expresión importante para comprender la dimensión personal de la vida humana: la libertad no es abstracta ni tampoco irrestricta; ella puede incluso implicar sacrificio y entrega a un objetivo o a otra persona a quien se ama, siempre y cuando quien haga dicho sacrificio esté consciente de su necesidad para la propia realización. Una vez más, es menester evocar el concepto de heroísmo de la voluntad tratado en el apartado anterior: la voluntad necesita luchar en contra de la adversidad de las circunstancias para que la persona por lo menos intente realizar el proyecto vital anhelado. El proyecto es autorreferencial, en el sentido de que cada persona puede percibirlo e intentar realizarlo. Aunque fracase por coacción externa - ya dentro de la circunstancia trágica — la persona sentirá que fracasó (como el personaje 
de Ramón) por su propia culpa, especialmente si es veraz al punto de percibir el poco esfuerzo emprendido para realizar su voluntad.

Pero hay que añadir que ese balance, esa impresión aterradora de «no he vivido», se hace desde dentro de la vida, por muy escaso que sea el tiempo disponible; $y$, por no tratarse de una cosa definida por una naturaleza fija, sino por una libertad ilimitada, esa final impresión se puede modificar y hasta invertir: cabe una torsión que, desde la persona que se es, transforme la vida y la ponga a una luz nueva, aunque sea el último momento. (Marías, 1997, p. 29)

La dignidad humana, por lo tanto, cuando es comprendida en su contexto ontológico $\mathrm{y}$ total en la persona, se revela como rica en posibilidades cuyas manifestaciones pueden darse desde el fracaso existencial hasta la lucha heroica en contra de la circunstancia trágica que intenta disminuir a la persona y quien ella desea ser. El aspecto dramático de la vida humana y ese punto de vista de la voluntad heroica escrito por José Ortega y Gasset son algunas de las manifestaciones de la dignidad humana que, aunque necesiten ser encontradas en cada vida personal, poseen rasgos comunes y por ello pueden ser comprendidas por todas las personas.

\section{Despersonalización: renuncia y atenuación de la dignidad humana}

Para que se comprenda la vida humana en su totalidad, incluidas especialmente su dignidad intrínseca y la responsabilidad que es consecuencia de tal dignidad, un ejemplo literario como el visto en este artículo es de suma importancia. La literatura da forma artística a las distintas posibilidades humanas $\mathrm{y}$, dentro de esa misma forma, hace que tales posibilidades sean cercanas a todas las personas.

...los ojos del artista en algo han de distinguirse de los del hombre vulgar, y su distinción consiste en ver, como entre sombras y figuras, lo mismo que el filósofo alcanza por procedimientos discursivos, es decir, la médula de las cosas, y lo más esencial y recóndito de ellas. De donde procede que los grandes personajes creados por el arte (que a su manera es creación; y perdonen Zola y sus secuaces) tienen una vida mucho más palpitante y densa que la mayor parte de los seres pálidos y borrosos que vemos por el mundo. (Menéndez-Pelayo, 1908, p. 369)

La densidad de los personajes literarios tiene como resultado que a los ojos del lector ellos aparezcan con mayor claridad. Así puede el lector mirar hacia la propia vida, compararla a la del personaje y tomar también para sí algo de la forma figurada por el 
autor. Las vidas ficcionales interesan tanto porque son dramáticas: todo lo que se dice en una obra de arte literaria no es producto del acaso ni mucho menos de algún capricho del autor, pero tiene un sentido interno que permite una comprensión más profunda del personaje.

Y además de todo esto, la vida del personaje imaginado, que es creación espiritual, ofrece por eso mismo una máxima transparencia al pensamiento y permite sumergirse en ella hasta lo más hondo, sin tropiezo con la esencial opacidad de lo real. Ya veremos más adelante la importancia y la fecundidad que esto tiene. La historia de ficción, sin mezcla con la realidad en el sentido de las cosas, muestra el puro ejemplo del drama humano y a la vez la mayor adecuación y homogeneidad con el espíritu que intenta penetrarlo. Especialmente, claro es, cuando se trata de penetrarlo imaginativamente, al crearlo. Significa proyectarse fuera, en ajena desnudez transparente, a sí propio. (Marías, 1950, p. 38)

Una identificación considerable solamente es posible porque se encuentra en el personaje literario algo muy semejante a la vida real, es decir, el personaje piensa, siente, actúa y también tiene sus motivaciones. Las estructuras de las narraciones ficticias son dramáticas, como lo es la propia vida humana: "La vida humana tiene carácter dramático, porque no es una serie de actos o hechos, sino que acontece en la forma de que algo acontece a alguien" (Marías, 1994, p. 22).

En el ejemplo de este artículo, se puede ver cómo el personaje Ramón concibió un proyecto de vida para sí y, a la vez que intentaba concretizarlo, terminó presa de la fantasía de que ya lo había realizado: como Don Quijote en el palacio de los duques. "La vida humana es futuriza: está orientada o proyectada hacia el futuro. Es anticipación de sí misma; por tanto, imaginación rica detallada de algo que no existe pero que se ve como porvenir" (Marías, 1994, p. 17). La idea del porvenir es también esencial al proyecto humano maduro; es esencial porque la persona espera construir, espera llegar a ser, aquello —o mejor, quien — todavía no es.

A partir de la lección de Ortega, se ha percibido que el personaje Ramón llegó a creer que ya era un héroe y de esa manera renunció a la lucha: pasó de la conciencia de la circunstancia trágica a la comedia de huir de la propia realidad. Por su falta de madurez, Ramón desconsideró el elemento de irrealidad que también es intrínseco a la vida humana:

La persona, por su irrealidad, inseguridad y contingencia, es lo más vulnerable, pero con un núcleo invulnerable, precisamente porque nunca está «dada»: no se puede decir de ella «esto es», porque «está siendo», «va a ser», sin límite 
conocido. Consiste en innovación, siempre puede rectificar, arrepentirse, volver a empezar, en suma, renacer. (Marías, 1997, p. 17)

Cuando se habla de la dignidad humana, se suele pensar en ese núcleo intocable —o invulnerable como lo ha llamado Julián Marías - que no debería ser amenazado por el Estado ni mucho menos por las demás personas. Semejante discusión, claro está, es bastante importante. Los abusos a los derechos humanos permiten que el tema siempre regrese y es menester que lo sea así. Sin embargo, por lo que se discute en este trabajo, hace falta analizar todavía la dignidad humana bajo otro aspecto: el de su responsabilidad. Eso no significa que el primer aspecto, el de la invulnerabilidad, sea contrarrestado en esta discusión; por el contrario: tratar de la responsabilidad que trae la dignidad brinda al núcleo de la persona una dimensión aún más profunda.

La responsabilidad oriunda de la dignidad humana clama para que cada persona pueda estructurar su vida e intentar realizarse: fue lo que hizo Ramón. Como señaló Ortega, la voluntad heroica significa el vislumbre de algo mejor para sí y el consecuente esfuerzo para llegar a este punto; es el esfuerzo de la persona para convertirse en quien ella quisiera ser, a pesar de las adversidades. Solo la persona tiene tal posibilidad vital. Por ello, Marías (1997, p. 32) ha definido el hombre como el animal que tiene una vida humana. Tal vida — cada vida - es intrínsecamente interpretada por la persona.

Y esto nos lleva a pensar que la persona es siempre interpretada. No se olvide que la vida humana es forzosamente teoría intrínseca: es vivida como tal vida. En principio, esa interpretación es la propia de cada persona; pero cabe la interpretación ajena, recibida, de modo individual y personal — seducción, tentación, persuasión - o impersonal y colectivo — cambio de vigencias, manipulación por los medios de comunicación-. Había que tener en cuenta las interpretaciones sucesivas a lo largo de la vida y su grado de autenticidad, pasividad, imposición, falsificación. (Marías, 1997, p. 32)

Vivir es contar la propia historia en una narración capaz de albergar el proyecto vital deseado, la circunstancia actual y el esfuerzo necesario para que la circunstancia sea asimilada al proyecto. La vida humana, por lo tanto, nunca está dada (Marías, 1997, p. 42) y ni tampoco está acabada: "Es esencialmente imperfecta en el sentido literal y etimológico de la palabra: es incompleta, inacabada, se está haciendo siempre, en perpetua inconclusión" (1997, p. 92). La persona espera una realización, se dirige hacia ella y, sin embargo, reconoce que todavía no se ha completado. Ramón, al pensar en sí mismo ya 
como héroe, imaginó que no le hacía falta subir otro peldaño más y se quedó tristemente sorprendido al percibir que moriría en una cama y no herido en batalla.

Cuando Ramón fue de lo trágico a lo cómico — en la visión de Ortega y Gasset que se sigue en este artículo - renunció a una parte fundamental del carácter dramático de la vida humana. Parte de su narración se perdió cuando creyó que ella estaba ya concluida. Ramón renunció a la responsabilidad que era consecuencia de su dignidad y, por tal razón, cayó en la despersonalización. Sin embargo, esto no quiere decir que haya dejado de ser persona porque:

La vida puede transcurrir «despersonalizada», pero lo decisivo es que esto únicamente puede sucederle a una persona; es decir, ni siquiera voluntariamente puede anularse la condición últimamente personal: una persona no puede dejar de serlo, aunque lo acepte, por mucho que se esfuerce. (Marías, 1997, p. 28)

La despersonalización de Ramón fue libre y consentida. Él se dejó dominar por la propia fantasía y renunció a su proyecto vital desde el mismo momento en que pensó haberlo realizado. En realidad, la despersonalización siempre es libre y consentida (Marías, 1997, p. 89). Aun así, por lo que se ha visto en el texto de Ortega y Gasset, muy a menudo las circunstancias parecen influir en la persona de un modo negativo, para que ella no realice su proyecto vital.

La dispersión habitual de la vida hace problemática la concentración, condición imperiosa para el hallazgo de la propia persona. La vida de nuestros contemporáneos está «llena» de quehaceres impuestos, impersonales, que no brotan de la vocación personal, sino de las solicitaciones de la profesión, de las múltiples regulaciones, de la presión del Estado y de las diversas instituciones; más aún, de los impactos informativos que se reciben a lo largo de todos los días y que absorben la mayor parte de la atención posible. (Marías, 1997, p. 50)

A tales circunstancias negativas es que hace falta resistir desde el núcleo invulnerable de la persona, es decir, desde su dignidad misma. Cuando se habla de despersonalización, por lo tanto, no se quiere decir que la persona haya perdido una parte de su dignidad lo que no podría ocurrir - pero sí que la haya puesto hacia un lado por la propia falsa percepción de la vida o por no ser capaz de resistir lo suficiente a las presiones exteriores. 


\section{Método APAC: la unión del heroísmo de la voluntad y de la dignidad de la persona humana en la recuperación del condenado}

En el actual sistema penal brasileño, se puede ver con mucha claridad el peligro de la despersonalización: en cárceles abarrotadas y sin la menor señal de impulso al arrepentimiento, los condenados son depositados y olvidados por la sociedad. Los abusos concretos a la dignidad humana, que a su vez no tienen fundamento ni siquiera en el carácter de retribución de la pena, contribuyen para que el condenado salga de la cárcel peor que cuando llegó. "É possível dizer que nem os mandamentos da condenação para reprimir e prevenir delitos, nem o escopo da ressocialização têm sido alcançados na prática do sistema penitenciário atual" (Cachichi, 2019, p. 30).

El método APAC nació de la necesidad de recuperar la persona en su totalidad en el sistema penal. Dicho método ha surgido no para superar, sino para cumplir efectivamente la Ley de Ejecución Penal de Brasil — sobre todo si se tiene en cuenta que el presente sistema penal no logra cumplir su finalidad de recuperación-. Por tal razón, Ottoboni llama la atención en el hecho de que:

O objetivo da reclusão é recuperar, especialmente quando se sabe que as despesas de manutenção do preso pesam nos cofres públicos, e predomina a certeza de que ele voltará ao convívio da sociedade pior do que quando iniciou o cumprimento da pena.

Trata-se de uma fraude social não cuidar da socialização da pessoa que errou e que, por isso, foi privada da liberdade. É um embuste contra a sociedade ludibriada com o elevado índice de reincidência e com o crime organizado nos presídios, atemorizando a própria polícia. (2004, p. 96)

Los abusos a los derechos humanos, el descuido de los presos y de sus familias y el alto índice de reincidencia de los liberados del sistema penal, no son más que consecuencias de una mentalidad según la cual aquellas personas no importan. Aquí se podría pensar que ellas cometieron crímenes y que deben pagarlos — lo que es cierto-; pero tal retribución a ser dada mediante pena criminal solo ocurre cuando el criminal logra arrepentirse de su error y tiene el propósito de mejorar. El determinismo del que hablaba Ortega en la cita que aparece más arriba se muestra con alguna claridad en esa visión: si la persona, por un lado, no puede arrepentirse, entonces ella no tiene libertad humana ni voluntad alguna. Por otro lado, si ella no es más que una víctima de las circunstancias que "la han puesto" en la prisión, entonces tampoco tiene voluntad y no puede ser protagonista 
de su propia vida. Ambas visiones que ignoran al condenado como persona le quitan su dignidad humana.

La dignidad, como se ha visto, es intrínseca al ser humano y tiene diversas manifestaciones. Jamás desaparece, pero puede ser disminuida por coacciones externas y debilidades internas. En el caso del condenado dentro del sistema penal actual de Brasil, se ha afirmado que se siente un desecho: la autoestima desaparece por completo (Pereira, 2006, p. 90). Además de físicamente debilitado, psicológicamente está destruido y espiritualmente casi muerto. La vida en el crimen es materialista:

Na vida do crime não há espaço para o espiritual, tudo é só material, ela circula em torno do dinheiro. A vida do crime é essencialmente materialista, aliás, como toda a nossa sociedade. Assim, além do próprio corpo (físico) do recuperando, muitas vezes debilitado em especial pelas drogas, a metodologia visa a restabelecerlhe o espírito, a mente e o psicológico. É aqui que entra a espiritualidade como um dos grandes alicerces da transformação do homem na misericórdia divina. (Siqueira, Costa \& Cachichi, 2019, p. 268)

Sin poder vislumbrar — ni dentro ni fuera de la cárcel— cualquier posibilidad humana que no sea la bajeza y la satisfacción de deseos materiales, es bastante difícil hablar de recuperación. En buena medida, esa visión materialista - y determinista - de la vida está en toda la sociedad, de manera que, en ese sentido, las personas dentro de las cárceles no se diferencian demasiado de las que están fuera.

Determinism is quite as likely to lead to cruelty as it is certain to lead to cowardice. Determinism is not inconsistent with the cruel treatment of criminals. What it is (perhaps) inconsistent with is the generous treatment of criminals; with any appeal to their better feelings or encouragement in their moral struggle. (Chesterton, 1909, p. 42)

Por otro lado, si de hecho la vida no es más que eso, entonces aquellas personas encarceladas realmente necesitan ser dejadas hacia un lado y olvidadas. Tales ideas para nada se relacionan con la voluntad heroica: la persona que obedece a meros impulsos físicos y materiales no puede convocar la libertad a su favor; ella, en realidad, es un rehén. La libertad, dentro del concepto del heroísmo de la voluntad, consiste en el objetivo de ser alguien, una persona íntegra y verdadera, con una historia de vida. 
Si una persona no puede ver y ni siquiera anhelar más que objetivos materiales, entonces ella se disminuye como persona. Sin tener conciencia de ello, es la primera en negar su misma dignidad. Deseará solamente que el Estado la defienda de cualquiera que pueda molestar su satisfacción. He aquí el caso de las personas arrestadas: en realidad, también ellas querrían realizar objetivos materiales; pero fueron demasiado lejos, por lo menos en la visión de orden que se suele tener. Así, la dignidad humana es olvidada; es olvidada porque no es vivida, porque el precio de responder ante la propia vida y lidiar con las responsabilidades de la lucha en contra de las circunstancias adversas es demasiado alto. Si la visión determinista - y materialista — de la vida es llevada a sus últimas consecuencias, entonces o el criminal tendrá que ser eliminado de la sociedad o no tendrá ninguna culpa. En ese sentido, se puede mencionar el comentario que Chesterton ha dirigido a un señor Blatchford, para quien las condiciones de vida muchas veces empujaban a las personas a la criminalidad:

Mas o determinismo lhe atraiu através de outro sentimento bastante normal; um sentimento de imoderada compaixão. Ele chamou seu livro de panfletos deterministas de um apelo 'em nome dos párias'. E era óbvio que ele meditara bastante acerca do tipo de pessoa pobre e desonrada, e frequentemente oprimida, que ele realmente podia chamar de pária. Para ele, assim como para muitos outros homens de saudável - mas vago - sentimento moderno, a noção de pecador de fato se ligava inteiramente à noção de um beberrão ou de um vagabundo assaltante ou de uma espécie de malandro em guerra contra a sociedade. Nesse sistema social tão injusto que suportamos, é bastante provável que muitas dessas pessoas sejam punidas injustamente, que alguns não devam de forma alguma ser punidos, que alguns, talvez, não tenham responsabilidade alguma. E Blatchford, vendo-os irem em massa para as prisões, não sentiu nem mais nem menos que piedade pelo pobre e pelo desafortunado, o que era, na pior das hipóteses, um exagero ligeiramente desvirtuado da caridade cristã. Ele estava tão ansioso para perdoar que acabou negando a necessidade de perdão. (2012, pp. 213-214)

Si la persona no tiene culpa, no le hace falta arrepentirse; si no le hace falta arrepentirse, tampoco necesita el perdón. Y si existe alguien que no necesite arrepentirse de absolutamente nada en el relato de su vida, entonces tal persona es un juguete de las circunstancias y no tiene ninguna libertad. Pero la dignidad humana exige la libertad. "A dignidade inerente ao conceito de pessoa deve ser vista - mais do que nunca- em sentido integral nos dias de hoje, que abrange não apenas o aspecto material, psicológico, mas também o aspecto espiritual, artístico e ético do ser humano" (Cachichi, 2019, p. 37). 
La integral dignidad de la persona es lo que fundamenta el método APAC. Dicho método fue así definido por su fundador Mário Ottoboni:

...entidade que dispõe de um método de valorização humana, portanto de evangelização, para oferecer ao condenado condições de recuperar-se e com o propósito de proteger a sociedade, socorrer as vítimas e promover a Justiça Restaurativa. (2018, p. 25)

La recuperación y el arrepentimiento suponen, en el contexto del método APAC, la conciencia de un error cometido. Uno de los grandes desafíos de la vida humana, un desafío que también comprende el concepto de heroísmo de la voluntad, es el de la confesión de las propias faltas, de la propia miseria; de la aceptación del sufrimiento. Notar la propia bajeza y admitirla, al contrario de lo que puede parecer, es en la mayoría de las veces el primer paso que da la persona hacia el objetivo de convertirse en alguien mejor:

Si el alma no fuera más que bajeza, ni siquiera se daría cuenta de la bajeza; mas si se da cuenta, evidentemente hay en ella una alteza. Esta alteza está invisible en 'Las Memorias del Subterráneo'; pero ella es la que produce todas las memorias del subterráneo. Una nobleza terriblemente lastimada y herida resuella allí por la herida. (Castellani, 1997, p. 20)

Aquí una vez más es menester regresar al personaje Ramón: él ya se veía como héroe; cuando, sin embargo, cayó víctima de una enfermedad y no de una herida en la batalla, pasó a verse como indigno a sus propios ojos. Ramón pasó del heroísmo de la voluntad (trágico) a la comicidad de crear una fantasía y vivir en ella, alejándose de la realidad. Le faltó a Ramón reconocer la propia pequeñez: aceptar su circunstancia trágica, para él, sería mirar hacia el heroísmo deseado y, sin embargo, todavía percibirse menor que su objetivo; reconocer que le hacía falta bastante lucha para lograrlo. Esto sería la humildad, tan valorada dentro del método APAC: la persona digna es quien puede arrepentirse de un error cometido porque su dignidad implica libertad.

O progresso moral significa buscar virtudes, ter ação voltada para as virtudes. O progresso espiritual significa olhar para além do imanente e buscar o transcendente, justamente o que a APAC formará tanto no aspecto da valorização moral - o cultivo de virtudes como o respeito ao próximo, a justiça, o trabalho, buscar ser melhor para a família - e as virtudes espirituais que são cultivadas na 
APAC. Por último no aspecto político, que significa basicamente cooperar com a sociedade para que a coletividade progrida, para que o outro progrida, enxergar o outro e junto com ele construir algo que beneficie a todos. Tudo isso faz com que o egresso deixe a APAC mais autônomo e mais livre... (Cachichi, 2019, p. 255)

Santo Tomás de Aquino ha explicado en la Suma Teológica (I, II, c. 27, a2) que el bien "não pode ser amado se não for conhecido". El heroísmo de la voluntad consiste, como se ha dicho, en el esfuerzo y en el deseo que la persona tiene de ser mejor. Tal deseo solamente puede existir cuando: (a) la persona logra imaginar que existe algo mejor de lo que había vislumbrado hasta entonces; (b) reconoce su miseria ante tal posibilidad y no se ve desde luego como si la tuviese conquistado; y (c) acepta la lucha contra todas las circunstancias que intenten alejarla de la imagen de quien desea ser. Pero, hay que hacer hincapié en ello, solo una persona consciente de su dignidad intrínseca puede querer ser mejor, puede percibir tal mejora como necesidad en su vida. El método APAC, hincando sus raíces en la dignidad humana concretizada en el amor al prójimo, les enseña a los presos que ellos son personas dignas y que, por esa razón, tienen libertad de arrepentirse y esperanza para que puedan resistir a las circunstancias que los alejen de las personas en quienes desean convertirse.

\section{Conclusión}

En la escena de la muerte de Ramón en la novela La fiel infantería, el narrador cuenta que el personaje intentó hacer la señal de la cruz pero sus fuerzas no se lo permitieron; entonces su mano se le cayó sobre la faz en un gesto que parecía avergonzado. De esa narración el lector puede entender que, justo en el fin, Ramón reconoció su debilidad y la rabia que tenía de sí mismo disminuyó. En cualquier momento de la vida, la persona puede arrepentirse y humildemente reconocer quien es.

El hecho es que, a lo largo de su corta vida, Ramón pensó en el heroísmo y, para su pesar, creyó ya ser un héroe. Despreció, por lo menos en sí mismo, la debilidad que es inherente a todas las personas. Él, que podría ser un personaje trágico, se convirtió en uno de comedia. Siguió, sin saberlo, el ejemplo de Don Quijote en el palacio de los duques. El heroísmo de la voluntad, tal y como enseñado por Ortega y Gasset, necesita de la humildad para realizarse.

El método APAC, por haber nacido para resolver un problema concreto, realiza dicho heró́smo de la voluntad. Los fundadores, voluntarios e incluso los condenados, están conscientes de sus propias debilidades: es tal conciencia la que les permite mirar 
al prójimo y desear ayudarlo. Cuando el método APAC hace hincapié en la dignidad humana como esencial a la recuperación de las personas presas, quiere con esto demostrar que el arrepentimiento, la responsabilidad y la esperanza solo pueden ser posibles para las personas que son libres hasta el punto de desear y luchar por convertirse en mejores de lo que son.

\section{Referencias}

Cachichi, R., C., D. (2019). Método APAC: O Humanismo como Caminho para a Ressocialização do Preso. UNIVEM.

Castellani, L. (1997). Psicología Humana (2. ${ }^{\text {a }}$ ed.). Jauja.

Cervantes, M. (2005). Don Quijote de la Mancha, 2. Alianza Editorial.

Chesterton, G. K. (1909). Orthodoxy. The Bodley Head.

Chesterton, G. K. (2012). Autobiografia (Trad. R. Robson). Ecclesiae.

García Serrano, R. (1964). La fiel infantería. La Guerra (pp. 397-598). Fermín Uriarte.

Hervada, J. (1993). Los derechos inherentes a la dignidad de la persona humana. Escritos de Derecho Natural. EUNSA.

Machado, A. (2001). Poesías Completas. Espasa Calpe.

Marías, J. (1950). Miguel de Unamuno. Espasa Calpe.

Marías, J. (1994). Mapa del Mundo Personal. Alianza Editorial.

Marías, J. (1997). Persona. Alianza Editorial.

Menéndez-Pelayo, M. (1908). Estudios de Crítica Literaria. Tipografía de la Revista de Archivos.

Ortega y Gasset, J. (2016). Meditaciones del Quijote. Livre.

Ottoboni, M. (2004). Seja solução, não vítima! Justiça restaurativa, uma abordagem inovadora. Cidade Nova.

Ottoboni, M. (2018). Vamos matar o criminoso? Método APAC. O Lutador.

Pereira, M. F. (2006). É possível a recuperação do preso? Revista Jur. UNIJUS, 9(11), 189-202. http://www.revistas.uniube.br/index.php/unijus/article/ download/1035/1210.

Pieper, J. (2018). Virtudes Fundamentais (Trad. P. R. A. Pacheco). Cultor de Livros.

Pozzoli, L. Scarmanhã, B. O. S. G. \& Cachichi, R. C. D. (2019). Desafios e perspectivas do sistema penitenciário: a compreensão da descentralização dos presídios 
como proposta de Mário Ottoboni à luz da filosofia ético-política de Jacques Maritain. En Constitucionalismo e Direitos Fundamentais (pp. 161-178). Instituto Memória.

Pozzoli, L. \& Toledo, I., R. (2017). Análise do princípio constitucional da dignidade humana face a dimensão da afetividade e o direito fraternal. Problemata: Revista Internacional de Filosofia, 8(1), 178-190. https://periodicos.ufpb.br/ ojs/index.php/problemata/article/view/27851.

Razaboni Jr., R., B., Leão Jr.T., M., A., \& Sanches, R., C., F. (2018). A educação inclusiva para pessoas com deficiência e o papel da Unesco. Revista da Faculdade de Direito da UFRGS, (38), 140-153. https://seer.ufrgs.br/revfacdir/article/ view/77562.

Santo Tomás de Aquino. (2009). Suma Teológica III. Loyola.

Siqueira, G., Costa, I. G. \& Cachichi, R. C. D. (2019). Culpa e espiritualidade nas APACs. En Humanização e execução penal: o drama na efetividade do direito penal (pp. 264-274). Instituto Memória. 